\title{
A terminologia das redes sociais no Brasil: etapas metodológicas
}

\section{Social networks' terminology in Brazil: methodological steps}

\author{
Márcio Sales Santiago* \\ Juliana Bicalho Pinto** \\ Júlio Araújo***
}

Resumo: Este artigo objetiva apresentar as etapas metodológicas utilizadas no Projeto "Terminologia das Redes Sociais no Brasil" (TERMIREDES). Tais etapas foram desenvolvidas visando ao registro dos termos presentes em tutoriais das redes sociais. Baseamos nosso trabalho nos fundamentos teóricos e metodológicos da Terminologia, disciplina que tem o termo como objeto central de estudo. Para o desenvolvimento da proposição, assumimos as concepções de Krieger (2004) sobre o fato de a análise terminológica compreender o modo como se constituem os léxicos especializados, bem como a adoção de um valor metodológico a fim de orientar o reconhecimento da terminologia de áreas especializadas ou domínios temáticos que ainda não contam com uma sistematização no português do Brasil. Como resultado, apresentamos o modelo de ficha terminológica desenvolvido para o projeto de pesquisa em questão.

Palavras-chave: Terminologia; Termo; Ficha terminológica; Redes sociais; Tutorial.

Abstract: This paper presents the methodological steps used in the Project named "Social Networks' terminology in Brazil" (TERMIREDES). These steps were developed

\footnotetext{
* Doutor em Letras/Estudos da Linguagem pela Universidade Federal do Rio Grande do Sul (UFRGS). Pesquisador do CNPq/Funcap (modalidade Desenvolvimento Científico Regional - DCR) no Programa de Pós-Graduação em Linguística da Universidade Federal do Ceará (UFC). E-mail: mssantiago12@gmail.com

** Graduanda em Letras-Português/Francês na Universidade Federal do Ceará (UFC). Bolsista de Iniciação Científica do CNPq. E-mail: julianab81@gmail.com

*** Doutor em Linguística pela Universidade Federal do Ceará (UFC). Professor e pesquisador do Programa de Pós-Graduação em Linguística da UFC. E-mail: araujo.ufc@gmail.com
} 
SANTIAGO, M. S.; PINTO, J. B.; ARAújo, J. - A terminologia das redes sociais no Brasil: etapas metodológicas

to record the terms present in tutorials of social networks. To this end, we have based our research on the theoretical and methodological Terminology conceptions, discipline whose main object of study is the term. We have used notions by Krieger (2004) for the development of the analytical proposition. This author considers that the terminological analysis of a given area includes the way in which the specialized lexicons are constituted, as well as the adoption of a methodological criterion to guide the recognition of the terminology of specialized areas that do not have a systematization in Brazilian Portuguese. We present as a result a model of the terminology entry developed for this research project.

Keywords: Terminology; Term; Terminological entry; Social networks; Tutorial.

\section{Introdução}

$\mathrm{Na}$ sociedade atual, as redes sociais da internet passaram a ter uma grande relevância, haja vista o número crescente de usuários dessas ferramentas computacionais de interação social. É possível, portanto, entendêlas como pertencentes a um subdomínio temático originário de dois grandes campos que, a princípio, não têm relação alguma, mas que, diante da interrelação das ciências e das tecnologias no mundo contemporâneo, produzem novos domínios. Por outro lado, em oposição a uma noção que entende a língua como produto acabado, ou seja, incapaz de evoluir no plano lexical, percebese claramente que a linguagem deste domínio temático está em pleno desenvolvimento e cada vez mais presente no dia a dia das pessoas.

Por sua vez, ao compartilharem "as mais variadas e distintas espécies de informações e conhecimentos" (SANTIAGO, KRIEGER \& ARAúJo 2014: 386), as redes sociais se configuram como um cenário repleto de termos, uma vez que esses conhecimentos transmitidos possuem, por vezes, um caráter especializado. Tomamos como exemplo de uma das formas de transmissão de conhecimento especializado a linguagem presente nos tutoriais. 
SANTIAgO, M. S.; PInTO, J. B.; ARAújo, J. - A terminologia das redes sociais no Brasil: etapas metodológicas

No tocante a essas questões, o Projeto "Terminologia das Redes Sociais no Brasil" (TERMIREDES) ${ }^{1}$ tem como objetivo principal levantar dados que permitam uma discussão a respeito das características constitutivas do léxico das redes sociais da internet no Brasil, notadamente sobre os termos que figuram em tutoriais elaborados para usuários brasileiros. Para tanto, a pesquisa se apoia nas concepções teórico-metodológicas desenvolvidas pela Terminologia.

O intuito deste artigo é apresentar a metodologia adotada para o registro dos termos presentes nos tutoriais de redes sociais. Para tanto, faremos a apresentação do panorama teórico da Terminologia e de seu objeto de estudo principal - o termo -, os quais são de grande importância para a construção das bases metodológicas. Em seguida, trataremos do gênero tutorial de redes sociais, visto que sua caracterização favorece a observação de propriedades básicas. Essas propriedades têm como propósito a identificação das especificidades que se mostraram fundamentais para o estudo dos termos contidos nele. Posteriormente, passaremos à parte mais importante desenvolvida neste trabalho: a descrição das etapas metodológicas utilizadas na pesquisa. Como resultado, apresentamos a ferramenta elaborada para o registro dos termos, a ficha terminológica, instrumento indispensável para a realização de trabalhos ligados à pesquisa em Terminologia.

\section{Quadro teórico da Terminologia}

\footnotetext{
1 Este projeto conta com apoio do Conselho Nacional de Desenvolvimento Científico e Tecnológico (CNPq) e da Fundação Cearense de Apoio ao Desenvolvimento Científico e Tecnológico (FUNCAP) por meio da bolsa de pesquisa modalidade Desenvolvimento Científico Regional - DCR (processos $\mathrm{n}^{\circ} 350882 / 2013-4$ e $\mathrm{n}^{\circ}$ DCR-0024-00861.01.00/13) e do CNPq através da bolsa de pesquisa modalidade Iniciação Científica - PIBIC (processo $n^{\circ}$ 143389/2014-9). É desenvolvido no âmbito do Programa de Pós-Graduação em Linguística da Universidade Federal do Ceará e do grupo de pesquisa Hiperged.
} 
SANTIAGO, M. S.; PINTO, J. B.; ARAÚJO, J. - A terminologia das redes sociais no Brasil: etapas metodológicas

A Terminologia é a disciplina linguística responsável pela análise e pela descrição do léxico especializado, tendo o termo como objeto central de estudo teórico e aplicado. Tal componente pode ser entendido como a base de trocas comunicacionais nas diferentes áreas especializadas, sejam técnicas, científicas, tecnológicas ou temáticas.

No plano teórico, a Terminologia está voltada a questões relativas à identificação, ao modo de funcionamento, ao tratamento do léxico especializado e suas unidades. Já sua face aplicada orienta-se, sobretudo, à produção de glossários terminológicos, dicionários técnico-científicos e bases de dados terminológicos.

Convém mencionar que os seres humanos, já na Antiguidade, utilizavam palavras para expressar um conhecimento mais especializado. De acordo com Rondeau (1984: 1), “desde que se manifesta a linguagem, encontramo-nos na presença de línguas de especialidade; é assim que se encontra a terminologia dos filósofos gregos, a língua de negócios dos comerciantes cretas, os vocábulos especializados da arte militar etc.". Porém, à contraposição de sua antiguidade prática, a Terminologia, como campo científico, é mais recente.

Foi a partir dos trabalhos do engenheiro austríaco Eugen Wüster, entre as décadas de 1930 e 1970, que as bases da disciplina foram estabelecidas. Assim, com o intuito de garantir a univocidade comunicacional da ciência em âmbito internacional, os estudos de Wüster deram origem à chamada Teoria Geral da Terminologia (TGT), de caráter prescritivo, que entende o termo apenas como uma unidade conceitual. De acordo com Krieger e Finatto (2004: 33), para essa visão wüsteriana

[...] muito contribuiu a concepção de que os termos são designações de conhecimentos científicos. Em consequência, os termos não são vistos como elementos naturais das línguas naturais, pois são compreendidos como unidades de conhecimento que comportam denominações. Nessa ótica, os conceitos científicos são identificados por meio de rótulos, etiquetas denominativas criadas com determinadas peculiaridades que permitem fugir das ambiguidades do léxico comum. 
SANTIAgo, M. S.; PINTO, J. B.; ARAújo, J. - A terminologia das redes sociais no Brasil: etapas metodológicas

Nas duas últimas décadas do século $X X$, entretanto, os estudos em Terminologia ganham uma nova visão ao abordarem os termos sob o ponto de vista linguístico e descritivo. A partir desse momento, a unidade terminológica começa a ser vista não apenas como uma unidade conceitual, mas também linguística, ou seja, as terminologias, que antes eram consideradas uma língua à parte, passam a ser compreendidas e estudadas como uma outra unidade qualquer da língua. Nesta abordagem, podemos citar as contribuições da Socioterminologia, surgida no Canadá nos anos 1980, com os pesquisadores Boulanger e Auger. Neste contexto, destaca-se o trabalho desenvolvido por Gaudin (1993), que discute com mais particularidade a influência da terminologia direcionada para o social, quando diz que:

[...] a socioterminologia, com o suposto de que deseja ultrapassar os limites de uma terminologia 'de escrivão', deve localizar a gênese dos termos, sua recepção, sua aceitação, mas também as causas do insucesso e as do sucesso, no âmbito das práticas linguísticas e sociais concretas dos homens que empregam tais termos. Estas práticas são essencialmente aquelas que se exercem nas esferas de atividade (GAUDIN 1993: 216).

É nesse momento dos estudos terminológicos que a situação comunicacional passa a ser levada em conta. Os contextos de ocorrência da unidade terminológica tornam-se também alvo de estudos e começam a permitir um melhor entendimento sobre as manifestações e comportamentos do termo em uma situação comunicativa real. Destaca-se, neste período, a Teoria Comunicativa da Terminologia (TCT), proposta por Cabré (1999), em Barcelona. De acordo com a autora:

A TCT não concebe a Terminologia como uma matéria autônoma, mas mantendo seu caráter intrinsecamente interdisciplinar, intenta explicá-la dentro de uma teoria da linguagem [...]. Deve oferecer critérios para descrever as unidades denominativas monossêmicas ou polivalentes e definir os limites desta variação. Tem que admitir a 
SANTIAGO, M. S.; PINTO, J. B.; ARAÚJO, J. - A terminologia das redes sociais no Brasil: etapas metodológicas

sinonímia como um fenômeno real dentro da comunicação especializada natural e oferecer critérios para esclarecer o distinto valor das unidades, se for o caso. Terá que levar em conta que as unidades terminológicas se dão de modo natural no discurso e, em consequência, têm uma projeção sintática além dos limites denominativos e variam em função do discurso. Deve contemplar a variação mesma do discurso e estabelecer as variáveis pertinentes que descrevem essa variação dentro da comunicação em geral e da especializada em particular (CABRÉ 1999: 122-124).

Outra visão dos estudos terminológicos pode ser encontrada nos postulados teóricos da Teoria Sociocognitiva da Terminologia, de Temmerman (2000). De acordo com essa teoria, “os termos são unidades de compreensão e de representação, funcionando em modelos cognitivos e culturais [...] e estão em constante evolução" (KRIEGER \& FinATTO 2004: 37). Frente a essa nova concepção de termo, as pesquisas que são fundamentadas pelas teorias textuais ganharam enorme valor.

A revisão teórica realizada principalmente por Gaudin, Cabré e Temmerman à teoria de Wüster caracteriza uma ruptura epistemológica significativa na história da ciência terminológica. As novas concepções assumidas desde então são atualmente bastante visíveis no estudo e no tratamento do termo, que passa a ser entendido como unidade representativa, comunicacional, que exerce e sofre todas as implicações sistêmicas e textuais próprias de toda e qualquer unidade linguística.

Há ainda avanços bem atuais nos estudos terminológicos, e estes crescem cada vez mais. Esses avanços dizem respeito ao enfoque textual que se tem dado ao se tratar de unidades terminológicas. Com esses estudos voltados para a Linguística Textual, passa-se a reconhecer a importância dos aspectos da textualidade e da discursividade na constituição dos termos. Sobre a importância dessa relação entre Terminologia e texto, Krieger e Finatto (2004: 108) afirmam:

O reconhecimento de que é preciso considerar os contextos linguísticos de ocorrência para dar conta da gênese e do 
SANTIAGO, M. S.; PINTO, J. B.; ARAújo, J. - A terminologia das redes sociais no Brasil: etapas metodológicas

funcionamento das terminologias evidencia que o quadro das propriedades semio-narrativas dos diferentes universos de discurso, incluindo tipologias e propósitos particulares das comunicações especializadas, está se impondo como uma produtiva orientação metodológica para detectar o estatuto terminológico de uma unidade lexical que se instaura como tal, dada sua relação semântica e pragmática com o texto especializado.

Com a evolução dos estudos terminológicos, novas noções sobre a unidade lexical especializada, objeto central da Terminologia, vão ganhando espaço. Como visto anteriormente, caminha-se de uma visão prescritiva e normatizadora, focada apenas na ideia do termo enquanto unidade cognitiva, até uma visão mais abrangente, em que o termo passa a ser considerado unidade cognitiva, linguística e comunicacional. A partir dessa evolução, percebe-se a flexibilidade dos termos, pois eles podem ocorrer em vários contextos diferentes, dependendo de sua pertinência para determinada área. Além disso, um mesmo termo pode, por exemplo, ter significações diferenciadas, é a situação comunicativa que vai ditar suas diferentes ocorrências.

Enquanto unidade linguística, sujeita aos mesmos processos linguísticos de outra unidade qualquer da língua, o termo se apresenta como uma estrutura complexa e requer os mesmos procedimentos de análise. Sendo assim, estudos de análise linguística em torno do termo podem contribuir para uma melhor compreensão do comportamento, da atuação e das estruturações dessas unidades em seus contextos de ocorrência.

A tarefa de identificação de um termo não é fácil, nem óbvia, porém é extremamente necessária, uma vez que, ao reconhecer os diversos enfoques dados a essa unidade, pode-se compreender melhor seu funcionamento e sua importância dentro de uma determinada área. Como elemento central das comunicações especializadas, o termo é uma unidade linguística que designa conceitos, objetos e processos. Para Gouadec (1990: 3), “o termo é a unidade de designação de elementos do universo percebido ou concebido". 
SANTIAGO, M. S.; PINTO, J. B.; ARAÚJO, J. - A terminologia das redes sociais no Brasil: etapas metodológicas

Para compreendermos um pouco melhor a importância das terminologias para as áreas do conhecimento, tomamos emprestada a ideia brilhante de Benveniste (1989), ao afirmar que um campo só se torna científico a partir do momento em que impõe seus conceitos e suas denominações. Segundo o autor, a ciência

[...] não tem outro meio de estabelecer sua legitimidade senão por especificar seu objeto denominando-o, podendo este constituir uma ordem de fenômenos, um domínio novo ou um modo novo de relações entre certos dados. 0 aparelhamento mental consiste, em primeiro lugar, de um inventário de termos que arrolam, configuram ou analisam a realidade. Denominar, isto é, criar um conceito, é, ao mesmo tempo, a primeira e última operação de uma ciência (BENVENISTE 1989: 252).

As ideias de Gouadec e de Benveniste se aproximam, uma vez que o termo é visto como uma unidade que serve para representar, descrever não somente os conceitos, mas tudo aquilo que a percepção humana é capaz de apreender e que seja de natureza específica.

Confirmando a ideia do termo enquanto unidade linguística e comunicativa que sofre variações e diferentes interpretações, a depender da área de especificidade e do contexto, Cabré (1993: 119) afirma que:

Os termos não formam parte de um sistema independente das palavras, mas que conformam com elas o léxico do falante, mas ao mesmo tempo, pelo fato de serem multidimensionais, podem ser analisados de outras perspectivas e compartilham com outros signos de sistemas não linguísticos o espaço da comunicação especializada.

Para Santiago, Krieger e Araújo (2014: 388), “os termos não são apenas rótulos, posto que revelam sua naturalidade aos sistemas linguísticos de várias formas, a iniciar pela consonância aos padrões morfossintáticos das línguas que os veiculam". Mais uma vez, tem-se a ideia da complexidade e da abrangência do termo, principalmente por se constituir em unidade também linguística, passível de todos os processos linguísticos previstos em uma dada língua. 
SANTIAgo, M. S.; PINTO, J. B.; ARAújo, J. - A terminologia das redes sociais no Brasil: etapas metodológicas

Cabré (1999) salienta a existência de uma diversidade de posicionamentos sobre a natureza do termo, especialmente por se tratar de uma unidade complexa que tende a se ampliar cada vez mais. Para a autora, por conta de sua complexidade, o termo é uma unidade não linear, ou seja, é uma unidade poliédrica.

De forma mais abrangente, podemos afirmar que a função do termo não é apenas de denominação, mas também de descrição, de representação e de fixação de uma realidade de natureza especializada.

Diante de toda essa complexidade que se pôde observar sobre o termo, não é possível referir-se a ele apenas como uma unidade cognitiva estática ou um bloco monolítico. Uma vez percebido como unidade linguística e comunicativa, o termo passa, então, a adquirir características e a sofrer mudanças, por exemplo, de caráter morfológico, sintático e semântico, como outras unidades lexicais. Até mesmo seus significados podem variar, de acordo com a área de especialidade em que estiver inserido.

Por integrar o sistema estrutural das línguas e, com isso, comportar-se como outra unidade lexical qualquer, as fronteiras que separam a unidade especializada da unidade lexical tornam-se mais fluidas. Para isso, mais uma vez se ressalta a importância de se levar em consideração a situação comunicativa, os contextos de realização. É em seu habitat natural, ou seja, nos textos especializados, de caráter técnico, científico, tecnológico e temático, que se torna possível a sua determinação enquanto termo e que se verifica a sua pertinência para determinada área.

\section{Os tutoriais de redes sociais}

No Projeto TERMIREDES, escolhemos trabalhar com os tutoriais, pois esses são considerados textos representativos do domínio temático em estudo. Em outras palavras, são os documentos genuínos elaborados pelos próprios desenvolvedores de cada rede para orientar o uso desses ambientes digitais. 
SANTIAGO, M. S.; PINTO, J. B.; ARAÚJO, J. - A terminologia das redes sociais no Brasil: etapas metodológicas

Assim, são considerados os tutoriais pertencentes às redes sociais Facebook, Twitter e Linkedln.

De acordo a noção de Santiago (2013: 37), “o tutorial é considerado um gênero textual, uma vez que está ambientado em um certo domínio social de comunicação, possui um dado público-alvo e um propósito bastante claro que o determina". Para o autor, os tutoriais são gêneros textuais cuja função é a de instrumentalização de usuários que estejam envolvidos e que precisem operar ferramentas informatizadas:

[...] os tutoriais são caracterizados como textos instrucionais que são elaborados propendendo à utilização de um sistema baseado nas indicações nele mostradas. Para tanto, é utilizada uma linguagem permeada de termos, unidades fraseológicas especializadas e conceitos próprios das áreas envolvidas (SANTIAGO 2013: 37).

No caso dos tutoriais de redes sociais, os usuários são instrumentalizados para a utilização de ferramentas pertencentes principalmente ao campo da Informática. Por fazer grande interface com essa área de estudos, espera-se que o indivíduo já possua algum conhecimento em informática, uma vez que em ambientes virtuais é de grande importância a compreensão dessa linguagem mais especializada.

Apesar de abrigar grande parte das unidades terminológicas, principalmente as oriundas do campo da Informática, Krieger e Finatto (2004: 113) ensinam que "a linguagem de especialidade não se resume à presença de termos técnicos, mas constitui-se do conjunto de todos os recursos linguísticos que se utilizam em um âmbito de comunicação". Complementando o pensamento das referidas autoras e ratificando a ideia de que um tutorial é um gênero textual de caráter especializado, cuja função é a de instrumentalizar, Santiago (2013: 38) afirma:

[...] recursos linguísticos, de ordem lexical, gramatical e textual, e também não linguísticos, tais como figuras, quadros, hiperlinks, setas etc., são empregados e incluem uma grande quantidade de situações de comunicação e expressão, já que há uma necessidade de ensinar 
SANTIAgo, M. S.; PINTO, J. B.; ARAújo, J. - A terminologia das redes sociais no Brasil: etapas metodológicas

a utilizar os recursos que serão empregados em uma situação particular. Por esta razão, entendemos que os tutoriais, por meio de uma comunicação especializada, possuem uma linguagem para fim específico.

Pode-se dizer, então, que os tutoriais das redes sociais utilizam um discurso especializado direcionado a uma finalidade específica, motivo pelo qual podem ser considerados, conforme Krieger (2001), um dos habitats das terminologias encontradas nessa área temática.

A partir dessas informações, e com base em Santiago, Krieger e Araújo (2014), podemos perceber algumas características importantes dos tutoriais de redes sociais, algumas delas já abordadas aqui, inclusive. A primeira dessas características é justamente a sua função: a instrumentalização de usuários. Outra característica é a pressuposição de que o usuário possua um conhecimento prévio mínimo sobre Informática. Uma terceira característica seria a linguagem com fim específico utilizada por esses tutoriais: ensinar o usuário a utilizar e navegar pela rede social; e também o uso de termos simples e sintagmas terminológicos, principalmente vindos da Informática.

De acordo com os referidos autores, ainda em se tratando das características, os tutoriais de redes sociais apresentam uma natureza injuntiva, na qual preponderam ações de dever-fazer. Porém, diferentemente de alguns tipos de tutorais, tais como os da Educação a Distância (EAD), os tutoriais das redes sociais demonstram uma preocupação em relação à compreensão do texto por parte do leitor. Para tanto, utilizam-se de “perguntas de satisfação” (SANTIAGO, KRIEGER \& ARAúJo 2014: 392) como, por exemplo: “essa resposta foi útil?”, “o conteúdo nesta página foi útil para você?”, “esta resposta ajudou?", entre outras.

\section{Etapas metodológicas}


SANTIAGO, M. S.; PINTO, J. B.; ARAÚJO, J. - A terminologia das redes sociais no Brasil: etapas metodológicas

O desenvolvimento da proposição analítica que ora apresentamos fundamentou-se no postulado de Krieger (2004), para quem a análise terminológica de uma determinada área compreende dois resultados significativos: uma contribuição teórica sobre o modo de constituição dos léxicos especializados e um valor metodológico que oriente o reconhecimento da terminologia de áreas especializadas ou domínios temáticos que ainda não contam com uma sistematização no português do Brasil.

Com o corpus previamente delimitado, passamos a realizar as tarefas de gerenciamento, sendo a primeira delas a compilação e organização. Em seguida, os tutoriais, que estavam em formato HTML, foram convertidos para TXT, já que este é o formato amplamente utilizado nos programas computacionais. Além disso, o texto em TXT torna o texto mais "limpo", isto é, sem imagens, figuras, caracteres ou algum outro elemento que não seja pertinente à pesquisa.

Como critério de organização, cada tutorial convertido foi salvo em pastas diferenciadas, sendo uma pasta específica para cada rede social. Cada arquivo em TXT foi nomeado de acordo com o título do tutorial em HTML, acrescido do nome da rede social à que pertencia, a fim de facilitar sua posterior identificação. Após essa conversão, nomeação e arquivamento em pastas específicas, chegou-se à compilação de 361 textos.

Em seguida, passou-se à análise dos tutoriais em busca de unidades lexicais que pudessem ser candidatos a termo. Uma primeira listagem contendo essas unidades foi elaborada. Para verificar como se dava a ocorrência dessas unidades nos contextos, utilizamos o AntConc 3.2.3w² (LAURENCE 2011), uma ferramenta de concordância que nos possibilitou determinar certas propriedades, tais como o contexto de ocorrência do candidato a termo nos tutoriais e sua frequência, conforme demonstramos na figura a seguir:

Figura 1: Tela da ferramenta AntConc 3.2.3w para a unidade amigo

\footnotetext{
${ }^{2}$ Disponibilizado gratuitamente em http://www.antlab.sci.waseda.ac.jp/antconc_index.html
} 
SANTIAGO, M. S.; PINTO, J. B.; ARAújo, J . - A terminologia das redes sociais no Brasil: etapas metodológicas

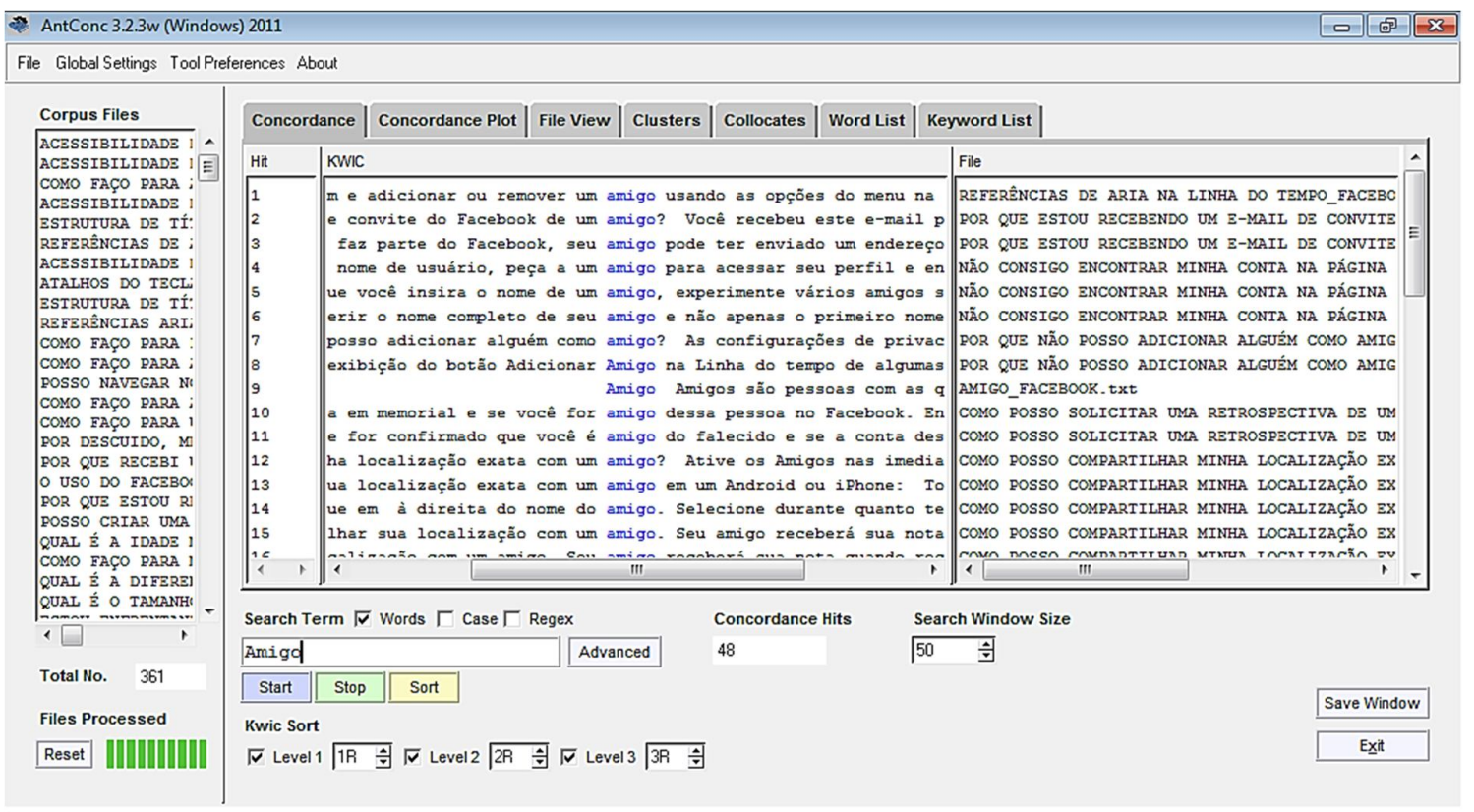

O concordanciador é de grande importância para a pesquisa, pois facilita o trabalho de busca por termos, suas informações no contexto, além de ajudar a perceber sua pertinência para as redes sociais. Com o avanço da leitura dos tutoriais, outras listas com candidatos foram criadas. A partir delas e das consultas feitas ao concordanciador, prosseguiu-se para a fase seguinte: o registro em fichas terminológicas, que são ferramentas imprescindíveis para trabalho de terminólogos.

As fichas terminológicas, de acordo com Cabré (1993: 281-282), "são materiais estruturados que devem conter toda a informação relevante sobre cada termo. As informações que apresentam são extraídas dos registros de seleção ou da documentação de referência, de acordo com os critérios estabelecidos previamente". Constituem-se, portanto, em um "verdadeiro dossiê sobre o termo" (KRIEGER \& FINATTO 2004: 154), já que nelas se concentram todas as informações pertinentes à pesquisa desenvolvida. Através delas, o pesquisador pode acessar rapidamente informações importantes sobre o termo e, consequentemente, pode agilizar todo o processo de análise. 
SANTIAGO, M. S.; PINTO, J. B.; ARAÚJO, J. - A terminologia das redes sociais no Brasil: etapas metodológicas

Vale ressaltar que a ficha terminológica foi, durante muito tempo, elaborada e preenchida através de um processo manual e não informatizado. 0 advento de computadores, de novos softwares e da internet permitiu que bancos de dados pudessem ser desenvolvidos em computadores pessoais, visando ao desenvolvimento de pesquisas personalizadas. Existem vários programas para elaboração de fichas e diversos bancos de dados terminológicos já desenvolvidos no Brasil e no mundo. Entretanto, a criação de uma ficha terminológica particular, voltada às especificidades do Projeto TERMIREDES, fez-se necessária.

O trabalho realizado pelo terminólogo conduzirá à confecção da ficha e esta poderá sofrer alterações durante todo o decorrer da investigação, uma vez que ela deve estar sempre ajustada à demanda da pesquisa. Apesar, porém, dessas possíveis modificações que acabam sendo necessárias, de acordo com Krieger e Finatto (2004), algumas informações são essenciais à ficha terminológica, tais como: entrada, informações sobre a denominação, aspectos gramaticais, abreviaturas, informações morfológicas, contextos de ocorrência, dados de gestão da ficha, entre outras.

Sendo assim, a ficha terminológica produzida para o Projeto TERMIREDES, que teve como critérios os pressupostos anteriormente citados, foi elaborada em uma base de dados no programa Microsoft Access 2013. As informações sobre os candidatos a termos foram organizadas em campos que serão relacionados e explicados adiante. Cabe salientar que esse modelo de ficha, resultado dos estudos sobre a pertinência de cada informação, poderá ser alterado conforme a necessidade da pesquisa em andamento. llustramos o modelo de ficha utilizada através da figura a seguir:

Figura 2: Ficha terminológica 
SANTIAGO, M. S.; PINTO, J. B.; ARAújo, J . - A terminologia das redes sociais no Brasil: etapas metodológicas

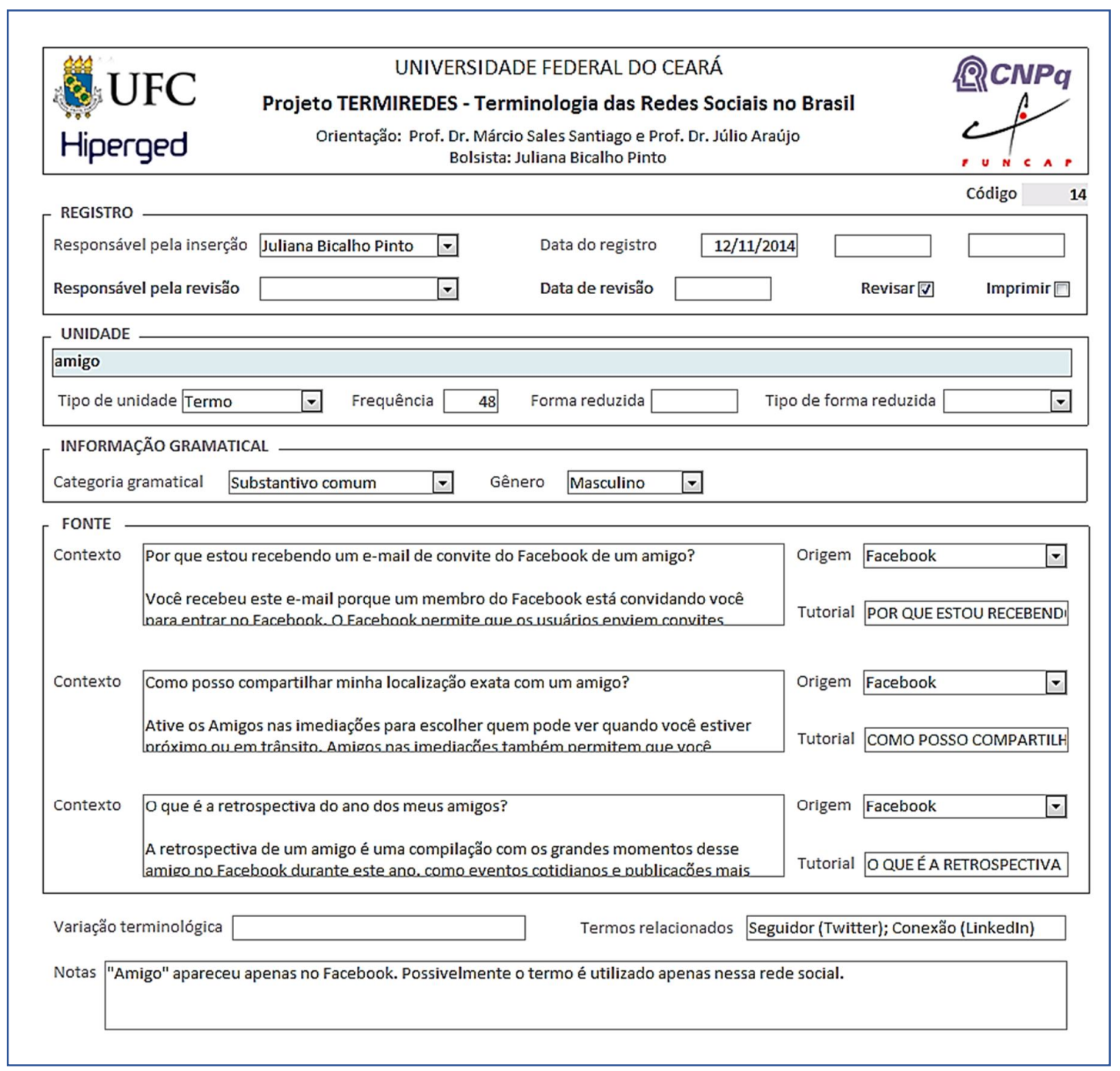

Como se pode observar, a ficha terminológica está dividida em quatro seções principais, além de incluir informações sobre variação terminológica, termos relacionados e notas complementares. Dentro dessas seções, encontram-se os campos com as informações consideradas mais pertinentes para o desenvolvimento da pesquisa.

O cabeçalho da ficha terminológica contém as informações relativas ao Projeto, como as instituições e grupos que estão ligados à pesquisa, bem como seus participantes. Logo abaixo do cabeçalho, verifica-se o campo "Código". Esse campo serve para organizar e ordenar de forma sequencial cada entrada 
SANTIAGO, M. S.; PINTO, J. B.; ARAÚJO, J. - A terminologia das redes sociais no Brasil: etapas metodológicas

no banco de dados da pesquisa. Com isso, facilita-se a localização futura dos registros.

A primeira seção, denominada "Registro", refere-se aos dados de gestão da ficha. Nessa parte da ficha encontram-se as informações sobre quando e por quem o termo foi registrado. No campo “Responsável pela inserção”, é possível selecionar em uma lista suspensa os nomes dos pesquisadores, especialistas e bolsistas envolvidos na pesquisa; a cada registro, marca-se o campo "Revisar" para que o pesquisador "Responsável pela revisão" possa fazer a verificação das informações adicionadas e confirmar ou não se a unidade candidata é um termo válido e representativo da área temática em questão.

Passando-se às informações relativas à denominação, a próxima seção da ficha é a "Unidade", contendo a entrada e algumas informações gerais sobre o candidato a termo. No campo “Tipo de unidade", faz-se a escolha se a unidade analisada pertence à categoria de termo ou de fraseologia especializada. Com os dados obtidos por meio do concordanciador AntConc, é possível informar a frequência de tal unidade. Nos tutoriais selecionados, se a unidade tem sigla, acrônimo ou forma alfanumérica, será registrada em "Formas reduzidas".

Ainda compondo as informações denominativas, a próxima seção permite o registro de algumas informações gramaticais acerca da unidade lexical especializada. Para o modelo de ficha proposto, julgou-se pertinente informar a "Categoria gramatical" do termo, podendo ser substantivo comum, substantivo próprio, adjetivo, verbo ou advérbio; em relação ao "Gênero", masculino, feminino, masculino/feminino.

Em seguida, vem a seção denominada “Fonte”. Nela, encontram-se informações referentes aos contextos de ocorrência do termo. Essa seção é de fundamental importância para a ficha, pois através dela é possível identificar em quais contextos de uso a unidade lexical especializada aparece. Além disso, pode-se também exemplificar e contextualizar as ocorrências do termo no texto de origem, neste caso, os tutoriais. De acordo com Krieger e Finatto (2004), 
SANTIAgo, M. S.; PINTO, J. B.; ARAújo, J. - A terminologia das redes sociais no Brasil: etapas metodológicas

essa aproximação entre as unidades terminológicas e o seu texto de ocorrência se justifica pois

[...] a relevância do texto está diretamente vinculada ao princípio comunicacional que postulam. Isso corresponde a considerar o texto como habitat natural das terminologias, bem como concebê-lo como objeto de comunicação entre destinador e destinatário (KRIEGER \& FINATTO 2004: 106).

Por esse motivo, analisar os termos em seus reais ambientes de ocorrência permite ao terminólogo observar seus comportamentos e características não de forma isolada, mas de forma contextualizada:

Ao mesmo tempo, tais proposições postulam o exame do comportamento das unidades terminológicas em seu real contexto de ocorrência, compreendendo que essas unidades aparecem de maneira natural no discurso, não constituindo uma língua à parte, como inicialmente se julgava (KRIEGER \& FINATTO 2004: 106-107).

Para o campo "Contexto", dentro da seção "Fonte", foram reservados três espaços sendo que, por meio do concordanciador, são selecionados os contextos mais representativos para aquela unidade. No campo “Origem”, é indicado a qual rede social o tutorial selecionado pertence, no caso da pesquisa em questão, se do Facebook, do Twitter ou do LinkedIn. Já no campo "Tutorial", encontra-se o título do tutorial que foi selecionado como contexto.

A última seção da ficha diz respeito às informações complementares sobre o termo. O campo "Variação terminológica" corresponde às variantes utilizadas nos tutoriais, as quais contemplam a diversidade terminológica utilizada neste gênero textual. Já o campo “Termos relacionados” é destinado à entrada de unidades que tenham alguma correspondência ou relação com o termo registrado. Por fim, no campo denominado “Notas", registram-se informações que possam trazer esclarecimentos e observações pertinentes ao termo daquela ficha. 
SANTIAGO, M. S.; PINTO, J. B.; ARAÚJO, J. - A terminologia das redes sociais no Brasil: etapas metodológicas

Após todo esse processo de registro dos candidatos a termos em fichas terminológicas, passa-se à fase seguinte, que corresponde à análise de cada candidato, por meio das informações adquiridas e registradas. Através dessa análise, que envolve os pressupostos teóricos mencionados anteriormente, mais alguns conhecimentos especializados sobre a área temática, verifica-se e certifica-se se o candidato é, de fato, uma unidade representativa daquela área e, com isso, se essa unidade se configura como um termo das redes sociais.

\section{Considerações finais}

Este artigo teve como objetivo mostrar o trabalho metodológico realizado durante a pesquisa desenvolvida no Projeto TERMIREDES e apresentar, como resultado, a ficha terminológica elaborada. Para tal, abordamos de forma breve as teorias que fundamentaram a pesquisa e descrevemos a maneira como se deu o processo de registro dos termos das redes sociais nessas fichas.

Diante do exposto, podemos dizer que todo o trabalho de gerenciamento dos dados é de fundamental importância para a pesquisa, uma vez que através desses procedimentos otimiza-se a tarefa de registro dos termos. Além disso, gerir todo esse conteúdo nos permitiu selecionar os paradigmas com vistas à elaboração da ficha terminológica. Através dela, torna-se possível realizar uma série de reflexões sobre a feição do léxico examinado, bem como o processo de formação dos termos no domínio das redes sociais.

Por fim, ao realizarmos estas etapas, ratificamos o quão importante e imprescindível elas são para a pesquisa em Terminologia. 0 acesso às informações essenciais dos termos sob a forma de fichas torna mais fácil e objetivo todo o processo de análise linguística. Sem essa ferramenta, dificilmente uma pesquisa dessa natureza tornar-se-ia possível devido ao grande volume de dados. Desse modo, elas são importantes para a organização dos dados recolhidos, ao mesmo tempo em que se gera uma complexa base de 
SANTIAgo, M. S.; PINTO, J. B.; ARAújo, J. - A terminologia das redes sociais no Brasil: etapas metodológicas

dados terminológica das redes sociais no Brasil, que poderá servir de referência para futuros trabalhos.

\section{Referências bibliográficas}

Benveniste, E. Problemas de linguística geral II. Campinas: Pontes, 1989.

CABRÉ, M. T. La Terminología: representación y comunicación. Barcelona: IULA/Universitat Pompeu Fabra, 1999.

CABRÉ, M. T. La Terminología: teoría, metodología, aplicaciones. Barcelona: Antártida/Empúries, 1993.

GAUDIN, F. Socioterminologie: des problèmes semantiques aux pratiques institutionnelles. Rouen: Publications de l'Université de Rouen, 1993.

GouADEC, D. Terminologie: constitution des données. Paris: AFNOR, 1990.

KRIEGER, M. G. Do reconhecimento de terminologias: entre o linguístico e o textual. In: Isquerdo, A. N.; Krieger, M. G. (Org.). As ciências do léxico: lexicologia, lexicografia, terminologia. v. 2. UFMS/UFRGS: Campo Grande/Porto Alegre, 2004: 327-339.

KRIEGER, M. G. O termo: questionamentos e configurações. In: KRIEGER, M. G.; MACIEL, A. M. B. (Org.). Temas de Terminologia. Porto Alegre/São Paulo: UFRGS/Humanitas/USP, 2001: 62-81.

Krieger, M. G.; FinAtTo, M. J. B. Introdução à Terminologia: teoria e prática. São Paulo: Contexto, 2004.

LaUrence, A. AntConc. Versão 3.2.3w (Windows). Tóquio: AntLab, 2011.

RondeAU, G. Introduction à la terminologie. Québec: Gaëtan Morin, 1984.

SANTIAGO, M. S. Unidades fraseológicas especializadas em tutoriais de ambientes virtuais de aprendizagem: proposta de um sistema classificatório com base na valência verbal. 223 f. Tese (Doutorado em Letras) - Universidade Federal do Rio Grande do Sul, Porto Alegre, 2013.

Santiago, M. S.; Krieger, M. G.; AraúJo, J. O gênero tutorial e a terminologia das redes sociais. Filologia e linguística portuguesa, v. 16, n. 2, São Paulo, jul./dez. 2014, pp. 381-402. 